\title{
Rancang Bangun Mesin Pemberi Pakan Ikan Otomatis Berbasis Internet of Things dan Sel Surya
}

\author{
Aris Suryadi ${ }^{1}$, Mindit Eriyadi ${ }^{2}$, Dede Jaelani ${ }^{3}$ \\ 1,2,3 Teknologi Listrik, Politeknik Enjinering Indorama \\ Kembang Kuning, Jatiluhur, Purwakarta, 41152 \\ ${ }^{1}$ aris.suryadi@pei.ac.id \\ ${ }^{2}$ mindit.eriyadiepei.ac.id \\ ${ }^{3}$ dedejaelani49@gmail.com
}

Intisari - Pemberian pakan ikan merupakan salah satu hal penting untuk usaha budidaya ikan. Saat ini pemberian pakan umumnya masih tergantung pada sumber daya manusia yang bersifat manual. Oleh karena itu dirancang alat untuk memberi pakan ikan yang dapat berkerja secara otomatis berdasarkan waktu atau jadwal pemberian pakan dan pengoprasian secara Internet of Things. Pemberian pakan ikan otomatis ini menggunakan hardware berupa Wimose D1 Mini yang merupakan pengongtrol utama, motor servo MG995 berfungsi untuk mengatur keluar nya pakan ikan dari tong penyimpanan pakan, sensor ultrasonik berfungsi untuk mendeteksi jumlah pakan yang tersedia di dalam wadah penyimpanan pakan yang di tampilkan secara IoT pada android. Motor DC berfungsi sebagai pelontar pakan pada saat pemberian makan ikan. Mesin pemberi pakan ikan berbasis IoT ini dapat dioperasikan secara Internet of Things, manual dan otomatis. yang di jalankan oleh smartphone android/aplikasi yang dapat dibuktikan dengan pengujian yang dilakukan dengan jarak $18 \mathrm{Km}$ dengan waktu respon kerja alat selama 1,48 detik, serta mampu menampilkan sisa pakan yang tersedia pada tong penyimpanan pakan berupa pemberitahuan ketika tampungan dalam keadaan kosong atau habis.

Kata kunci - Pemberian pakan otomatis, Internet of Things, Wemos D1 Mini.

Abstract - Fish feed is one of the important things for fish farming. Currently, feeding generally depends on manual human resources. Therefore, a tool to feed fish is designed that can work automatically based on the time or schedule of feeding and operating the Internet of Things. The provision of automatic fish feed uses hardware in the form of a Wimose D1 Mini which is the main controller, the Mg995 servo motor functions to regulate the release of fish feed from the feed storage barrel, the ultrasonic sensor functions to detect the amount of feed available in the feed storage container which is displayed IoT. on android. DC motor functions as a feed launcher when feeding fish. This IoT-based fish feeding machine can be operated on the Internet of Things, manually and automatically. which is run by an Android smartphone / application that can be proven by testing carried out at a distance of $18 \mathrm{Km}$ with a working response time of 1.48 seconds, as well as being able to display the remaining feed available in the feed storage bin in the form of a notification when the container is empty or runs out.

Keywords - Automatic Feeding, Internet of Things, Wemos D1 Mini.

\section{PENDAHULUAN}

Usaha budidaya ikan air tawar menjadi salah satu upaya penopang perekonomian masyarakat ditengah sulitnya lapangan pekerjaan maupun tuntutan kebutuhan yang meningkat [1]. Selain untuk mendapatkan keuntungan dari penjualan daging ikan yang marak berkembang [2]. Untuk meningkatkan hasil budidaya serta mempermudah kegiatan budidaya maka perlu adanya pengembangan teknologi di dalamnya.

$\begin{array}{llr}\text { Pakan mempunyai peranan } & \text { sangat } \\ \text { penting dalam pertumbuhan } & \text { dan } \\ \text { perkembangbiakan budidaya } & \text { ikan. }\end{array}$
Perkembangan teknologi digital memberikan solusi dalam sebuah sistem otomatis yang lebih baik [3]. Rancang bangun pemberi pakan ikan otomatis berbasis IoT dan sel surya adalah salah satu sistem elektronik yang dirancang untuk memberikan pakan 
secara otomatis tanpa harus ke kolam setiap hari guna untuk meringankan pemberian pakan secara manual [4].

Perancangan pemberi pakan ikan otomatis berbasis IoT dan sel surya pada kolam ikan ini dapat di atur penjadwalan pemberian makan ikan secara otomatis dan dilakukan pemberian makan ikan melalui aplikasi yang menggunakan sistem IoT Wemos D1 Mini [5], serta mesin pemberi pakan ikan ini menggunakan sumber listrik DC dari baterai yang di charger oleh cahaya matahari menggunakan panel surya sehingga mesin pemberi pakan ikan ini sangat efisien digunakan pada tambak ikan yang tidak tersuplai sumber listrik $220 \mathrm{~V}$ AC [6].

Perancangan alat ini, menggunakan Wemos D1 Mini sebagai pengolah data dan motor servo untuk mengatur pemberian pakan ikan, motor DC sebagai penebar pakan ke kolam ikan dan sensor ultrasonik sebagai pendeteksi jumlah pakan yang ada pada tempat penyimpanan pakan [7].

\section{METODE PENELITIAN}

\section{A. Rancangan Alat}

Mesin pemberi pakan ikan otomatis berbasis IoT dan sel Surya yang berbentuk sebuah tong penyimpanan pakan yang di operasikan secara IoT menggunakan sistem android/aplikasi. Motor Servo Mg995 berfungsi sebagai pintu buka tutup keluarnya pakan ikan dan dideteksi jumlah pakan yang tersedia di dalam tong menggunakan sensor ultrasonik sehingga jumlah pakan ikan yang tersedia di dalam tong penyimpanan terlihat sistem android/aplikasi. Pakan ikan di lontarkan menggunakan Kipas yang di koppel dengan motor DC $12 \mathrm{~V}$ sehingga pakan ikan terlontar jauh kedepan. Sumber yang di gunakan yaitu baterai $12 \mathrm{~V}$ yang di charge oleh panel surya 10WP.

\section{B. Diagram Blok}

Rancang bangun alat mesin pemberi pakan ikan otomatis berbasis IoT dan sel surya dapat di operasikan dengan cara manual, otomatis dan IoT. Untuk pengoprasian manual cukup dengan menekan tombol push button manual yang ada pada panel listrik. Wemos D1 Mini sebagai sistem pengontrol pengoprasian mesin pemberi pakan ikan ini. Sebagaimana terlihat pada gambar 1 diagram blok rancang alat pemberi pakan ikan.

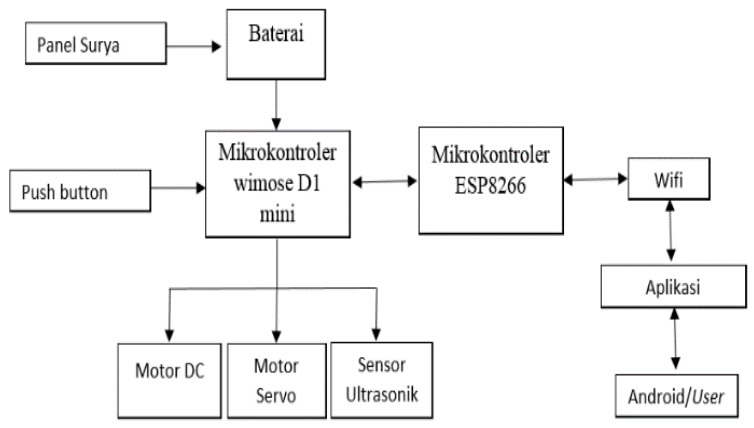

Gbr 1. Diagram blok rancang bangun alat

Dan untuk pengoperasian secara otomatis settingan mesin ini dengan penjadwalan waktu pengoprasian pada pukul 08:00, 10:00, 12:00, 14:00, dan 16:00 WIB, dan untuk pengoprasian secara IoT nya di oprasikan melalui sistem Android/aplikasi, yang di dalam aplikasi terdapat tombol tiga tombol untuk pemberian pakan ikan ini, yaitu tombol pemberian pakan secara sebentar, sedang, dan lama.

\section{Rancangan Mekanik}

Sebelum direalisasikan ke bentuk fisik, terlebih dahulu dilakukan perancangan alat untuk memudahkan pada saat pembuatan produk/mesin Berikut adalah bentuk kontruksi alat pemberi pakan ikan otomatis.

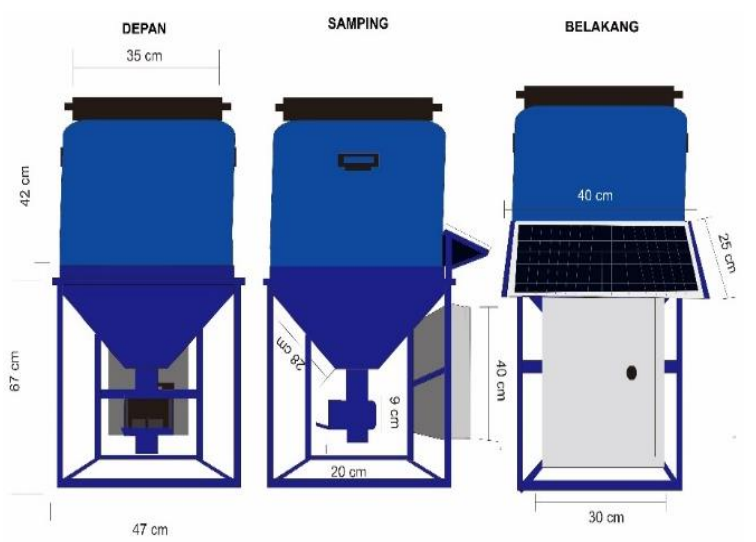

Gbr 2. Kontruksi mesin pemberi pakan ikan. 


\section{Rangkaian Elektrik}

Motor DC yang digunakan adalah motor type RS775 yang memiliki kecepatan 40008000 rpm. Pengontrolan menggunakan regulator speed motor. Pada gambar 3 diperlihatkan sebelum ke motor masuk dulu ke relay sebagai saklelar NO/NC. Pin yang digunakan untuk rangkaian motor DC. D0L1 relay, G-Ground relay, 3,3V-VCC relay, positif motor- NC relay, positif motor- positif regulator speed. NC relay- Negatif regulator speed.

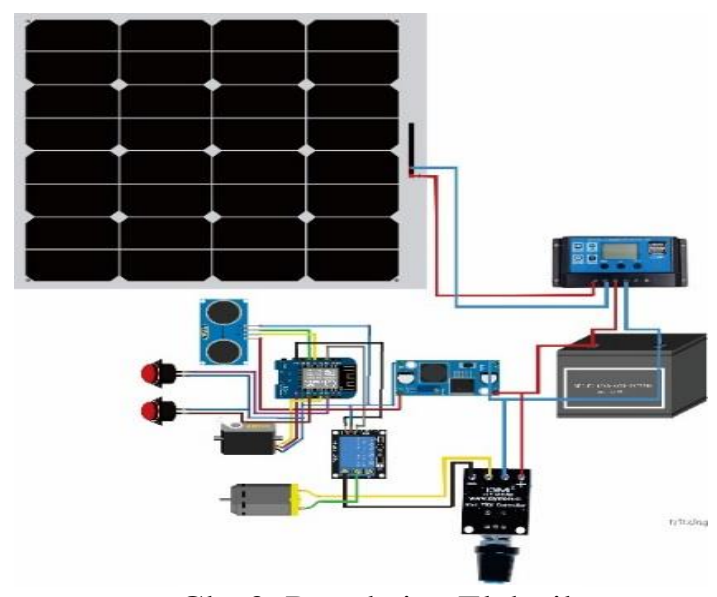

Gbr 3. Rangkaian Elektrik

\section{HASIL DAN PEMBAHASAN}

\section{A. Pengujian Fungsi Sistem Kontrol}

Pengujian keberfungsian alat sangat penting dilakukan karena berpengaruh pada kinerja sistem, modifikasi sistem maupun troubleshoot yang kemungkinan terjadi suatu hari. Berikut penulis menyajikan tabel keberfungsian alat yang telah diuji sebanyak 10 kali.

Tabel 1. Pengujian Fungsional Komponen

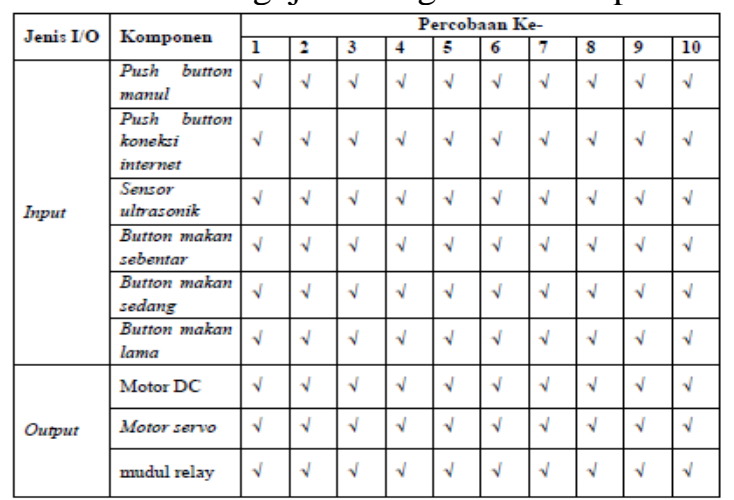

Keterangan : $[\sqrt{ }]$, Komponen berfungsi baik
Berdasar pada tabel 1, kondisi alat telah memenuhi pengujian dan dapat berfungsi sebagaimana yang telah direncanakan.

\section{B. Pengujian Komponen Alat}

Pengujian komponen pada alat dilakukan untuk mengetahui apakah parameter yang terukur pada setiap komponen bekerja sesuai dengan spesifikasi maupun nameplate yang tertera. Pada tabel 2 diperlihatkan hasil pengujian pada komponen.

Tabel 2. Pengujiankomponen alat

\begin{tabular}{|l|l|l|l|l|l|l|l|l|l|l|l|}
\hline \multirow{2}{*}{ Komponen } & \multirow{2}{*}{$\begin{array}{l}\text { Parameter } \\
\text { Pengukuran }\end{array}$} & \multicolumn{10}{|c|}{ Percobaan Ke- } \\
\cline { 2 - 13 } & $\mathbf{l}$ & $\mathbf{2}$ & $\mathbf{3}$ & $\mathbf{4}$ & $\mathbf{5}$ & $\mathbf{6}$ & $\mathbf{7}$ & $\mathbf{8}$ & $\mathbf{9}$ & $\mathbf{1 0}$ \\
\hline \multirow{3}{*}{ Panel surya } & $\begin{array}{l}\text { Tegangan } \\
\text { (V) }\end{array}$ & 12,55 & 12,23 & 12,25 & 12,28 & 12,30 & 12,34 & 12,35 & 12,35 & 12,36 & 12,36 \\
\cline { 2 - 13 } & Arus (A) & 0,59 & 0,38 & 0,37 & 0,62 & 0,61 & 0,62 & 0,63 & 0,61 & 0,62 & 0,59 \\
\hline \multirow{3}{*}{ Motor DC } & $\begin{array}{l}\text { Tegangan } \\
\text { (V) }\end{array}$ & 11,32 & 11,35 & 11,32 & 11,33 & 11,28 & 11,32 & 11,32 & 11,33 & 11,28 & 11,26 \\
\cline { 2 - 12 } & Arus (A) & 0,91 & 1,18 & 1,19 & 1,18 & 1,19 & 1,17 & 1,19 & 1,18 & 1,19 & 1,17 \\
\hline
\end{tabular}

\section{Pengujian Pengoperasian Jarak}

Pengujian ini bertujuan untuk mengetahui respon untuk menyalakan mesin pemberi pakan ikan pada saat tombol pada aplikasi ditekan yang dilakukan dengan jarak pengontrolan bervariasi, yaitu rentang antara 900 meter - 18 kilo meter.

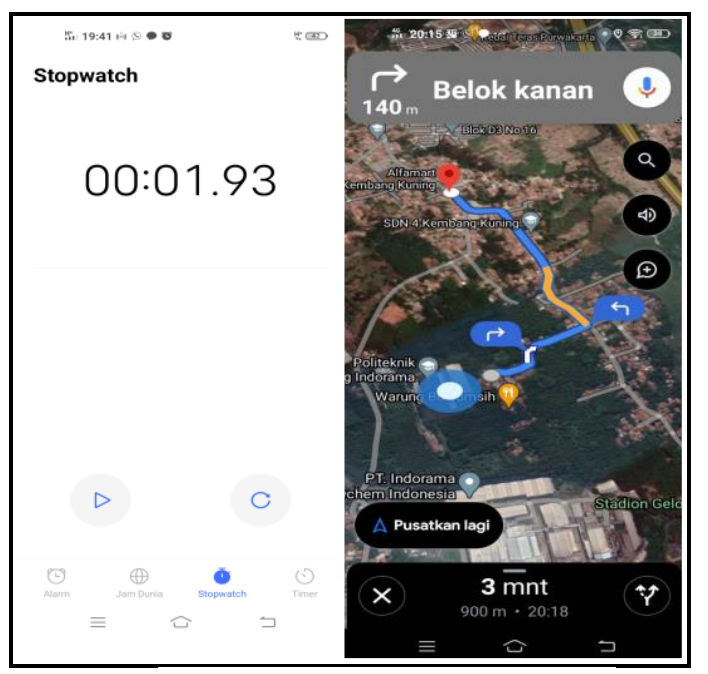

Gbr 4. Lokasi pengujian jarak

Gambar 4 diperlihatkan lokasi pengujian pada jarak yang dilakukan dengan jarak 900 meter dan mendapatkan waktu respon menyala selama 1,93 detik. Berikut tabel 3 merupakan data pengujian serta pengontrolan dalam jarak yang dilakukan adalah sebagai berikut : 
Tabel 3. Pengujian jarak

\begin{tabular}{|c|c|c|c|c|}
\hline $\begin{array}{c}\text { Penguji } \\
\text { an ke- }\end{array}$ & $\begin{array}{c}\text { Jarak } \\
(\mathbf{k m})\end{array}$ & $\begin{array}{c}\text { Respon kerja alat } \\
\text { (secon) }\end{array}$ & Lokasi pengujian & Keterangan \\
\hline $\mathbf{1}$ & 0,9 & 01,93 & Warung nangka ke PEI & Menyala \\
\hline $\mathbf{2}$ & 1 & 00,40 & $\begin{array}{c}\text { Kantor desa kembang kuning ke } \\
\text { PEI }\end{array}$ & menyala \\
\hline $\mathbf{3}$ & $\mathbf{3}$ & 01,29 & SPBU parcom ke PEI & Menyala \\
\hline $\mathbf{4}$ & 3,6 & 01,21 & Terminal Ciganea ke PEI & Menyala \\
\hline $\mathbf{6}$ & 18 & 02,57 & Sukatani ke PEI & Menyala \\
\hline
\end{tabular}

Berdasarkan tabel 3 pengujian jarak diatas, waktu respon pengoprasian secara IoT tidak terlalu lama merespon rata rata waktu respon menyalanya alat yang di operasikan secara IoT adalah 1,48 detik.

\section{KESIMPULAN}

Pengujian yang telah dilakukan bahwa penggunakan IoT untuk jarak rentang $900 \mathrm{~m}$ - $18 \mathrm{Km}$ mesin pemberi pakan ikan dapat bekerja dengan baik. Adapun respon kerja adalah sebesar 1,48 detik. Namun hal ini akan bergantung pada sinyal internet yang mempengaruhi respon pada saat menyalakan dengan sistem IoT.

\section{REFERENSI}

[1] Ariyanti, E.Y., Aman, M,. \& Rochmad. C. D. Perancangan dan Pembuatan sistem Penebar Pakan Ikan Jenis Pasta Otomatis Berbasis Mikrokontroler.

[2] Maulana, H., \& Julianto A. M. (2017) Pembangun sistem Smart-fishing berbasis Internet of Things Studi Kasus di Perternakan Ikan Mas Majalaya.

[3] Setiawan, Yoyok. (2017) Rancang Bangun Pemantauan dan Penjadwalan Alat Pemberi Makan Otomatis Secara Jarak Jauh. Surabaya: STIKOM.

[4] Waluyo, Agus., (2018) Pemberi Pakan Ikan Otomatis menggunakan ESP 8266 berbasis Internet of Things (IoT).

[5] Alblitary, khoir., (2017) Rancang Bangun Alat Pemberi Pakan Ikan Otomatis Pada Kolam Ikan Gurami Berbasis Arduino : ITS. 